\title{
Acercamientos teóricos y prácticos a las emociones en las elecciones
}

\section{Theoretical and practical approaches to emotions in elections}

\author{
Anna Maria Fernández Poncela iD \\ Universidad Autónoma Metropolitana, México. \\ fpam1721@correo.xoc.uam.mx
}

\begin{abstract}
Resumen
El objetivo de este texto es plantear un acercamiento a la relación entre las emociones, las elecciones presidenciales en México 2018 y el papel que en esta relación juegan la teoría de la inteligencia afectiva, los sentimientos morales y la evaluación cognitivo-emocional. Se estudian las emociones y las preferencias electorales, la posible incidencia de las primeras sobre las segundas, así como su relación con las teorías. Esto se hace a través de una encuesta en la ciudad de México y entrevistas pre y post electorales. Como resultado se confirma el importante papel que jugaron las emociones en la elección, su influencia en las preferencias, así como la polarización político-emocional que tuvo lugar.
\end{abstract}

Palabras clave: política, voto, candidatos, teorías, estudio empírico, México.

\begin{abstract}
An approach to the relationships between emotions and presidential election in Mexico 2018 is this text objective, and the role of the theory of emotional intelligence, the moral feelings and emotional cognitive evaluation. Explores the emotions and voter preferences, the potential impact of the former on the latter, as well as their relationship with the theories. This is done through a survey in the city of Mexico and interviews pre and post election. Affirm the importance of the role of emotions in the election as a result, and their influence in the preferences, as well as, polarization emotional politician in this moment.
\end{abstract}

Keywords: politics, voting, candidates, theories, empirical study, Mexico.

Articulo: Recibido el 3 de marzo de 2020 y aprobado el 11 de noviembre de 2020

\section{Introducción}

En la actualidad hay varios acercamientos, desde las ciencias sociales, al papel de las emociones en la política y el sufragio. Son teorias de alcance medio, pues todavía se está investigando cómo funciona el cerebro político-emocional, cómo influyen las estrategias de persuasión y seducción afectiva, cómo se construyen los marcos de percepción, se crean estados de ánimos, qué papel juegan los medios y, en fin, un sinnúmero de aspectos que unidos dan luz, finalmente, a cómo se decide el voto y se vota.

$\mathrm{El}$ objetivo de este trabajo es esclarecer la relación entre elecciones y emociones, de manera particular la influencia de las segundas en las primeras, entender cómo las perspectivas teóricas esbozadas enmarcan esta relación y la acompañan; y cómo la información en cifras y las narrativas ilustran, a través de un estudio de caso, la realidad social.

\section{Cómo citar este artículo:}

Fernández Poncela, A.M. (2021). Acercamientos teóricos y prácticos a las emociones en las elecciones. Reflexión política 23(47), pp. 7-26. doi: https://doi.org/10.29375/01240781.3857 
Elegimos tres enfoques teóricos con el objetivo de guiar y orientar la investigación sobre el papel de las emociones en las elecciones presidenciales de México 2018: la teoría de la inteligencia afectiva de Marcus, la evaluación cognitiva en los juicios morales de Nussbaum y las baterías de emociones y sentimientos morales de Jaspers. Estas teorías son antecedentes contextuales de lo que se estudia y se busca que inspiren y guíen, como se ha dicho, la parte empírica del estudio. ${ }^{1}$

En primer lugar, se presentarán brevemente las perspectivas teóricas y a continuación, con la información de una encuesta preelectoral y de entrevistas pre y post electorales, analizar y reflexionar sobre las mismas según el estudio de caso seleccionado.

En cuanto a la metodología de la parte práctica de este trabajo se cuenta con los resultados de una encuesta preelectoral llevada a cabo en la ciudad de México y compuesta de 800 casos. Esta misma aporta las preferencias electorales y las emociones en torno a ellas: lo que la gente dice que sentiría si gana o si no gana su candidato presidencial. También incluye cifras que orientan de forma cuantitativa y extensiva el tema.

Por otra parte, con el propósito de obtener un acercamiento más cualitativo y significativo, se realizaron 118 entrevistas antes de la elección y 127 entrevistas tras ella, sobre el papel de las emociones en el sufragio en general y, en particular, sobre las elecciones presidenciales que se avecinaban y que pasaron: cuáles eran sus preferencias electorales, entretejidas con sus emociones, si obtenía la victoria su candidato preferido o si no lo hacía. ${ }^{2}$

\section{La teoria}

\subsection{La Inteligencia afectiva}

La inteligencia afectiva es una teoría que alumbra la importancia de las emociones en la política, en concreto en los procesos electorales. George Marcus (2002) es su creador y, junto a otros autores, han aportado estudios de caso sobre la aplicación de la misma. Más allá de su consistencia, esta teoría es importante como guía y orientación de investigaciones empíricas como la que nos ocupa. Posee aspectos cognitivos y algo de la teoría de la elección racional con sus matices.

Según la inteligencia afectiva cogniciones y emociones se procesan de manera conjunta y colaboran mutuamente, "las emociones realzan la racionalidad del ciudadano porque le permiten ajustar sus juicios políticos a las circunstancias" (Marcus, Neuman y Mackuenn, 2007b, p.265), todo ello en concordancia con estudios de otras ciencias (Damasio, 2006). Además, "argumenta que el compromiso emocional motivará a la gente a tomar decisiones políticas más razonadas que quienes permanecen desapasionados" (Marcus, Neuman y Mackuenn, 2007a,p. 253). Esto parece claro, ya que la emoción es la que mueve a la acción (Filliozat, 2007), por lo tanto, quien esté más emocionado con la política más participará en la misma y lo hará de forma más consciente y consistente.

El modelo de inteligencia afectiva sugiere que los votantes tienen dos modos alternativos de tomar decisiones: el primero[...]es la casual, incluso impensada, confianza en las disposiciones habituales; el segundo es la consideración razonada[...]los ciudadanos se desvían de sus juicios rutinarios cuando están emocionalmente involucrados, produciendo juicios más razonados y comprometidos[...]la ansiedad puede mover a la gente a poner más atención a la política y a conseguir información nueva y más precisa (Marcus, Neuman y Mackuenn, 2007a, p.253).

1. Si bien desde la psicología hay autores como David Eagleman (2013; 2017) o Daniel Khanemann (2013) que reflexionan sobre la toma de decisiones, así como quienes desde la comunicación política se acercan al tema, aquí se han seleccionado las obras de sociología que se consideran más

2. Latisfactorias para el desarrollo de la investigación de la cual se deriva el presente artículo. de datos de manera descriptiva se procederá a comentarlos según las teorías expuestas, hasta donde sea posible. También se emplearán otras obras y autores que abordan directa o indirectamente el tema. Quizás sería más correcto hablar de sentimientos como los define Damasio (2006) y aprovechar la diferencia que establece entre estas y las emociones. Sin embargo, como la mayoría de la literatura existente se refiere a emociones, se ha decidido emplear dicho concepto. 
Este último punto es uno de los más criticados, se arguye que para que la gente participe de forma consciente y racional debe estar temerosa o como mínimo nerviosa.

Se parte de que hay dos sistemas en el cerebro límbico: el sistema de disposición afectiva y el sistema de vigilancia. El primero se inclina por las decisiones habituales, impensadas, del pasado, del cotidiano, fincadas en el aprendizaje adquirido y la rutina, en lo conocido donde se acumulan decisiones repetidas que facilitan la vida porque o no se informa o la información coincide con las expectativas o las creencias de siempre. Este sistema tiene lugar usualmente en un ambiente benigno, de calma emocional y confianza en los hábitos. Para efectos electorales este sistema se evidencia en que la preferencia electoral y el ejercicio del sufragio tiende a ser por el partido en el poder, por el voto por tradición personal, familiar o grupal, incluso quien oferte confianza. Se dice que entre las emociones de esta posición destaca también el entusiasmo que tiene que ver con la esperanza, que activa la decisión de votar por un determinado personaje o fuerza política muchas veces guiados por la capacidad del líder político y el sentimiento de compromiso en la campaña, que despiertan o avivan dichos sentimientos. También se habla del orgullo junto con la esperanza.

Por otro lado, el sistema de vigilancia se activa cuando la situación rutinaria se ve interrumpida por una influencia externa, en principio incongruente con la coherencia interna. Se genera una disonancia cognitiva, dos pensamientos o creencias en conflicto, una sensación de amenaza $\mathrm{y}$, sobre todo, resalta la ansiedad. Esto lleva, en primer lugar, a prestar más atención, a buscar información, pensar en novedades, razonar más profundamente y reconsiderar las antiguas opciones ante la intranquilidad que se siente. Además, se tiende a cuestionar los juicios iniciales, se abandonan las predisposiciones y se estimula el interés y el pensar de otra manera. "Cuando la gente siente peligro no solo se fija más en el mundo exterior, sino que además compromete su conciencia para pensar qué hacer. Los mismos mecanismos se aplican a la política" (Marcus, Neuman y Mackuenn, 2007b, p.251). Se considera que los votantes sopesan las cualidades personales y posturas políticas de los líderes y las comparan con sus propias preferencias partidarias usuales, evalúan las posibles ventajas del cambio y, en fin, hay cognición y racionalidad. Por lo tanto, en cuanto a opciones político-electorales, este sistema conlleva cambio de preferencias guiado por la ansiedad y por la mayor focalización de la atención en la contienda, lo que genera una mayor racionalidad y desenvuelve el juicio y la acción política en una dirección determinada, en general de cambio.

Finalmente es importante recordar que el entusiasmo es traducido electoralmente en apoyo y la ansiedad en todo lo contrario. El entusiasmo, que según esta teoría convoca a la elección de un candidato, es una respuesta rutinaria de repertorios aprendidos, desde una actitud más complaciente. La ansiedad se refleja en el sistema de vigilancia, ante una supuesta o real amenaza cuando se reconsideran o confrontan las formas habituales de pensar, se deja de confiar en el hábito y se confía más en la nueva información y en la reflexión aparentemente racional, se trata de una posición política más en la línea del oponente. De hecho las emociones negativas como esta "están asociadas con deserciones mayores del partidismo" (Marcus, Neuman y Mackuenn, 2007b,p.250). Si bien no ha sido tan atendido desde esta perspectiva, también el enojo podría incluirse, la ira y hartazgo conducirian a activar el sistema de vigilancia, si no tanto en la reflexión consciente, sí en el inconformismo con el estado de las cosas y en la transformación de la forma de pensar, las preferencias electorales y el voto.

\subsection{Sentimientos morales y baterias emocionales}

Si hay un estudioso destacado de las emociones en los movimientos y protesta social es el sociólogo estadounidense James M. Jasper. Su enfoque construccionista se basa en las emociones como parte de la cultura, la cognición y la moral (Jasper, 1997). Combina pensamiento, sentimiento y evaluación de la información, especialmente en procesamientos cognitivos de las emociones morales complejas. Aquí retomamos su concepción de lo emocional como origen de la protesta y del proceso emocional en los cursos de acción colectiva, los cuales también dan luz a las emociones en las elecciones. Para el estudio empírico que aquí se realiza su propuesta tiene mucho que decir.

Este autor coincide con la corriente anterior en que las emociones centran la atención 
de un actor sobre el mundo, afirma que "cuando los votantes se sienten amenazados, sus emociones reflejas los llevan a buscar información adicional y a procesarla de forma minuciosa” (Jasper, 2013, p.47). Incluso, añade:

La ansiedad también ayuda a incorporar gente para nuevas formas de acción, incluida la protesta. Una manera en que los activistas intentan el reclutamiento es a través de la creación o el aprovechamiento de shocks morales: informaciones o eventos [...] les sugieran a las personas que el mundo no es como piensan. Su malestar visceral los conduce a veces a la acción política en busca de reparación (Jasper, 2013, p.53).

Todo lo anterior tiene que ver con movimientos, partidos-movimientos o con movilizaciones en torno a un candidato.

Este autor, entre otras cosas, tiene en cuenta que las emociones están dentro de un proceso o continuum emocional, como la psicología y terapias predican (Muñoz, 2009), además subraya cómo interactúan entre ellas. En cuanto a su concepción de las emociones en la política afirma que "la manifestación de las emociones siempre ayuda (y nunca perjudica) a la movilización y los objetivos de la protesta". Luego Nussbaum, entre otros autores, diferenciará los tipos políticos de protesta y las consecuencias destructivas y violentas de algunas de ellas. Entre las funciones en los movimientos de protesta de las emociones, el autor considera que "motivan a los individuos, se generan en la multitud, se expresan retóricamente y dan forma a los objetivos manifiestos y latentes de los movimientos" (Jasper, 2013, p.47). En uno de sus trabajos, presenta una enumeración basada en cómo se sienten las emociones y su duración: pulsiones que considera impulsos corporales y necesidades de sobrevivencia —aquí el psicoanálisis o la pirámide de Maslow tienen algo de influencia emociones reflejas como reacciones al entorno físico y social, de rápida duración, sentidas y expresadas en el cuerpo - esto es, emociones propiamente dichas desde la óptica de Damasio, o la reacción emocional de la Gestalt_, estados de ánimo con duración temporal - y emociones "reflexivas" - entre los estados de ánimo y las reflejas. Sobre estas últimas conviene hacer un alto para traer sus propias palabras:
El primero, las lealtades $\mathrm{u}$ orientaciones afectivas son apegos o aversiones: amor, simpatía, respeto, confianza, admiración, y sus equivalentes negativos [...] ligadas [...] a valoraciones cognitivas elaboradas en relación con los otros [...] Por otra parte, las emociones morales — segundo tipo- se refieren a los sentimientos de aprobación o rechazo basados en intuiciones o principios morales; así mismo están relacionadas con la satisfacción de hacer lo correcto (o incorrecto), como por ejemplo la compasión en torno a los desamparados o la indignación frente a la injusticia (Jasper, 2013,p.48).

Tanto la consideración de principios subyacentes a las emociones, el destacado papel de la compasión y la indignación por una sociedad injusta, también son coincidentes con Nussbaum.

Sobre el proceso emocional destaca que, si bien el shock moral saca de rutinas, centra atención y persuade, las emociones también colaboran en el mantenimiento de un movimiento porque aportan satisfacciones a partir de identidades colectivas, solidaridades y rituales de interacción. Esto es, se comparten emociones reflejas y lealtades afectivas, se trata de las emociones compartidas y recíprocas. Todo ello genera una energía emocional motivadora, entre la confianza, la satisfacción e incluso la alegría de estar juntos, por un lado, y las emociones hacia el enemigo, por el otro, que también unen. Así, las emociones empujan a la acción, y también son parte de un flujo de interacción en el tiempo. "Las rutinas de la protesta deben ofrecer satisfacciones [...] Los placeres de la conversación, el entusiasmo de la interacción, la habilidad para articular instituciones morales, la sensación de estar haciendo historia, etc., son satisfacciones que mantienen a los participantes en la carrera” (Jaspers, 2013, p. 58).

La identidad colectiva y los lazos afectivos de un grupo de protesta son importantes (Jasper, 2012) por supuesto entre los activistas de una formación política y en el transcurso de las campañas electorales. Se destaca la experiencia vivida y se cuestiona: ¿qué es lo que quiere la gente?. "En la medida en que los estudiosos regresen a los temas de la motivación y a los fines de la acción, a los puntos de vista de la propia gente, podrán ofrecer mejores respuestas que las que brindan los estructuralistas o los racionalistas" (Jasper, 2012, p.38). La anterior transcripción presenta un enfoque metodológico, las emociones auto reportadas. 
Otro concepto relevante es el de "batería de emociones". "La esperanza es a menudo el polo positivo de lo que llamo batería moral: la combinación de emociones positivas o negativas que, a través de su contraste, proveen energía a la acción" (Jasper, 2013, p.52). Este concepto se retoma en estas páginas pues se combinan ansiedad y entusiasmo, como señala Marcus, o entusiasmo y enojo —cómo serán las cosas frente a lo que podrían y deberían ser y cómo el refuerzo complementario de ambas influye en preferencia electoral-, como se presenta aquí.

Su opinión sobre la ira o el enojo es que "puede sugerir una visceral ola de pánico por algo oculto, o una elaborada indignación sobre la insensibilidad de nuestro gobierno" (Jasper, 2013, p.47). Al respecto añade en otro momento: "La indignación frente al propio gobierno puede ser especialmente motivadora, ya que involucra un sentimiento de traición” (Jasper, 2013, p.53). Ahonda diciendo que se combinan emociones positivas con negativas, su tensión y contraste demanda atención y acción, si bien esto es algo que aparece en las campañas.

Una forma más genérica de batería moral mezcla la esperanza por el cambio futuro con el miedo, la ansiedad, y otros sufrimientos del presente. Los organizadores más exitosos exageran la propuesta del futuro tanto como el sufrimiento del presente. El terrible contraste entre la manera como son las cosas ahora y la forma en que podrían ser ayuda a motivar la protesta y la acción política (Jasper, 2013, p.53).

Está claro dentro de su enfoque y clasificación cómo los estados de ánimos con referentes externos -, los compromisos o lealtades afectivas - estables, positivas o negativas, amor y odio, confianza o desconfianza, aprecio o desprecio-, las emociones morales —aprobación o desaprobación, orgullo, indignación, furia, compasión - la energía emocional —entusiasmo, agitación-, el shock moral, las emociones morales -orgullo y vergüenza- y las emociones compartidas o recíprocas - la solidaridad dentro del grupo o la ira contra el adversario- contribuyen a la acción política de todo tipo. "Las emociones son una parte medular de la acción" (Jasper, 2013, p.60). Destacamos, para los efectos de este trabajo, el shock moral, las lealtades y, sobre todo, las emociones o sentimientos morales por su repercusión en la elección: la indignación o el enojo y el compromiso o entusiasmo. Al respecto, algo que también señala Jasper, citando a Snow y Gamson, son los marcos -esquemas interpretativos que simplifican y condensan el mundo-, en especial los "marcos de injusticia" y su componente emocional que se da desde creencias compartidas en los lazos afectivos —especialmente indignación y enojo- y desde emociones fuertes que movilizan.

De otro lado, se considera que la pasión de la justicia contiene esperanza por lo que se combinan emociones negativas como la amenaza, el enojo, la indignación, o el miedo como se vio con anterioridad, con emociones positivas, tales como, la esperanza, la dicha y la compasión. Por otra parte, eso sí, votar significa poca participación y estar en un movimiento social mucha, no obstante, algunas de las emociones de los segundos tienen clara relación con la acción primera.

\subsection{Emociones cognitivas y juicios morales}

Si hay una autora contemporánea preocupada por introducir las emociones en la política liberal y entender su empleo benéfico en el juicio moral, es la filósofa estadounidense Martha Nussbaum. Algunos de sus conceptos y reflexiones son útiles para pensar las emociones en época de elecciones. Las emociones según ella involucran la evaluación y son parte del florecimiento de la persona (Nussbaum, 2012).

Concebir las emociones como elementos esenciales de la inteligencia humana, y no como meros apoyos [...]proporciona unas razones especialmente poderosas para fomentar las condiciones del bienestar emocional en una cultura política, pues esta concepción implica que, sin desarrollo emocional, una parte de la capacidad de razonar como criaturas políticas desaparecerá (Nussbaum, 2012, pp.23-24).

Todo lo anterior también según Damasio (2006). La emoción es así parte de lo que considera el desarrollo personal y la convivencia social. Las emociones se relacionan con apetitos, estados de ánimo y motivos para la acción desde una teoría cognitiva-evaluativa, fundamentalmente una forma de pensamiento evaluativo, no obstante, según su reflexión, se deberían ocupar de la moralidad. Éstas “comportan juicios relativos a cosas importantes, 
evaluaciones en las que, atribuyendo a un objeto externo relevancia para nuestro bienestar, reconocemos nuestra naturaleza necesitada e incompleta frente a porciones del mundo que no controlamos plenamente" (Nussbaum, 2012, p.41). Aristóteles dice que las emociones influyen en los juicios y viceversa (1990).

Aquí se parte de la premisa de que "todas las sociedades están llenas de emociones. Las democracias liberales no son ninguna excepción” (Nussbaum, 2014, p.13). Sentimientos como la compasión ante la pérdida, o la indignación frente la injusticia, son algunos de ellos. Su propuesta es cultivar sentimientos apropiados, la simpatía y el amor dentro de su concepto de justicia e igualdad, la redistribución y la inclusión, todo en una sociedad liberal. Una sociedad que reconoce imperfecta pero aspiracional. Inspirándose en Rawls y otros autores habla de justicia y compromiso, de la necesidad de que las emociones sirvan a las instituciones para el bien común, lo cual también ha significado una crítica pues otros afirman que esta perspectiva descuida el énfasis en la violencia y el dolor según algunos.

Una de las emociones que sobresale en la perspectiva de esta autora es la compasión, con objeto de "motivar y sostener la acción altruista y las instituciones igualitarias" (Nussbaum, 2014, p.37), también el miedo, la envidia y la vergüenza las considera emociones sociales destacadas en la política. Subraya la importancia de los sueños e ideales como motivación política. Otra emoción relevante en su exposición es la ira, que subdivide en rabia, cólera, enfado y furia - sin mencionar que éstas son aquella en diferentes grados de intensidad y direccionalidad-.

La ira, en la vertiente de castigo o venganza al perpetrador, es una forma poner límites a los otros, de disuadir una agresión. La ira posee una utilidad instrumental de tres maneras: es necesaria para proteger la dignidad y el respeto a uno mismo, frente a las faltas para tratar con seriedad al malhechor, y "es una parte esencial del combate contra la injusticia” (Nussbaum, 2018, p. 24), "es importante pues es un sentimiento de reivindicación de la dignidad humanitaria de los oprimidos y una expresión del respeto por los seres humanos como finalidad. El tratamiento de la esfera política se divide en dos partes: justicia cotidiana y justicia revolucionaria” (Nussbaum, 2018, p.26). Cita a Gandhi y a Luther King, siguiendo sus escritos la ira no es necesaria para la justicia, incluso siendo un impedimento para la generosidad y la empatía, por lo que afirma posee una utilidad limitada y es una guía falsa de las situaciones revolucionarias; testigo de esa generosidad es la vida de Mandela. De ahí que esta autora aluda al perdón, como virtud política y personal. Sin embargo, no olvida como otros autores le recriminan que la ira es destructiva y dañina en ocasiones, no obstante, ante la inseguridad personal y la vulnerabilidad, contribuye a restaurar el control perdido. Le preocupan los actos injustos y el papel del estado. En todo caso, reconoce y remarca la ira noble, cuando la sociedad es corrupta y brutal. Y, como se dijo, desempeña tres papeles valiosos, ya que:

"los oprimidos reconocen el mal que se ha cometido en su contra [...] motivación necesaria para que protesten y luchen contra esa injusticia y para que comuniquen al mundo la naturaleza de sus reclamos [...] la indignación ante las injusticias terribles, está bien y, por consiguiente, la ira expresa algo verdadero" (Nussbaum, 2018,p. 328).

Este punto tiene que ver con las elecciones y con el estudio que se lleva a cabo en estas páginas.

Una vez expuestas estas propuestas teóricas sobre emociones y política, vamos a relacionarlas con un estudio sobre las emociones en las elecciones presidenciales en 2018 en México, reflexionando sobre la implicación emocional en el acto de votar.

\section{Las emociones en la campaña presidencial del 2018}

"Así, encontramos que la gente insegura sobre el estado actual del país estaba tanto más entusiasmada como más ansiosa sobre las propuestas de un cambio radical, más próxima al compromiso en el debate y a desarrollar ambas reacciones emocionales" (Marcus, Neuman y Mackuenn, 2007a, p.259). Entusiasmo y ansiedad (Markus, Newman y Mackuenn, 2007a) se combinan en una batería moral de aprobación y rechazo, esperanza y enojo (Jaspers, 2013). Esta se une a su vez con las necesarias emociones morales de indignación y compromiso (Nussbaum, 2014). Reiteramos, las teorías mencionadas o algunas partes de estas sirven únicamente para enmarcar el estudio empírico y para un acercamiento de los datos obtenidos. 


\subsection{Encuesta}

La "Encuesta preelectoral de la Ciudad de México 2018" (Tabla 1) se realizó en el mes de junio del año 2018, días antes de la jornada electoral. Su objetivo fue medir la información preelectoral, la cultura política y la participación ciudadana, a estas categorías se añadieron preguntas que entrecruzan preferencias electorales y emociones en torno a los candidatos -Andrés Manuel López Obrador (AMLO), Ricardo Anaya Cortés (RAC), Juan Antonio Meade Kuribreña (JAMK) y Jaime Rodríguez Calderón (JRC) $-^{3}$ en caso de ganar o de no hacerlo.

Tabla 1. La muestra

\begin{tabular}{cccccccccc} 
Sexo & & Edad & & $\begin{array}{c}\text { Nivel } \\
\text { escolar }\end{array}$ & & \multicolumn{2}{c}{$\begin{array}{c}\text { Sector } \\
\text { productivo }\end{array}$} & \multicolumn{3}{c}{ Ocupación } \\
\hline Hombres & $48.8 \%$ & $18-29$ & $29.3 \%$ & Sin estudios & $5.1 \%$ & Sector público & $22.8 \%$ & Trabajadores & $43.8 \%$ \\
\hline Mujeres & $51.3 \%$ & $30-44$ & $32.8 \%$ & Primaria & $10.5 \%$ & Sector privado & $34.1 \%$ & Autoempleados & $13.3 \%$ \\
\hline & & $45 \mathrm{y}+$ & $38 \%$ & Secundaria & $22.4 \%$ & Cuenta propia & $43 \%$ & Desempleados & $7.3 \%$ \\
\hline & & & Bachillerato & $36 \%$ & & & Amas de casa & $17.4 \%$ \\
\hline & & & Universidad & $26 \%$ & & & Estudiantes & $13.3 \%$ \\
\hline & & & & & & & Jubilados & $5.1 \%$
\end{tabular}

Fuente: Elaboración propia con base en los datos de la Encuesta preelectoral de la Ciudad de México, junio 2018.

También se presenta en la Tabla 2 la intención de voto, la cual es importante tener en cuenta para la revisión emocional que se va a realizar a continuación.

Tabla 2. Preferencias electorales e intención de voto

Si hoy fuera el día de las elecciones ¿usted por qué candidato votaria para presidente de la república?

\begin{tabular}{cc}
\hline AMLO & $52,13 \%$ \\
\hline RAC & $17,25 \%$ \\
\hline JAMK & $7 \%$ \\
\hline
\end{tabular}

\begin{tabular}{cc}
\hline No sabe todavía & $7 \%$ \\
\hline JRC & $4,13 \%$ \\
\hline Ninguno & $2,63 \%$
\end{tabular}

\begin{tabular}{cc}
\hline No acudiré a votar & $2,63 \%$ \\
\hline Anularé mi voto & $2 \%$ \\
\hline Votaré en blanco & $0,50 \%$ \\
\hline No contestó & $4,75 \%$
\end{tabular}

Fuente: Elaboración propia con base en los datos de la Encuesta preelectoral de la Ciudad de México, junio 2018.

Sobre el tema electoral y emocional en concreto un interrogante decía: "Si mañana fueran las elecciones ¿cómo se sentiría si gana?” A continuación, se nombraban los cuatro candidatos presidenciales y las cuatro emociones seleccionadas como respuesta de opción múltiple ${ }^{4}$. Luego hubo una pregunta similar que indagaba sobre la posibilidad opuesta así: "Si mañana fueran las elecciones ¿cómo se sentiría si no gana?" y enseguida se nombraba a los candidatos $\mathrm{y}$ a las cuatro emociones.

Como se observa en la Tabla 3 hay una clara polarización emocional, es importante recordar que la encuesta se aplicó en la ciudad de México y un importante porcentaje (52.13\%) de los participantes afirmó que sufragaría por Andrés Manuel López Obrador (Tabla 2). Los resultados de la encuesta, comparados con los datos de las elecciones, presentan porcentajes similares.

La polarización emocional si gana o no gana determinado candidato viene relacionada con la intención de voto y preferencia electoral. Sabiendo que más de la mitad de la muestra de la encuesta dijo votaría por AMLO, es normal que un elevado porcentaje $(43.9 \%)$ diga que sentirá esperanza si este candidato triunfa en los comicios y que, si no lo hace, casi la mitad (49.1\%) afirme que sentirá enojo. Por el contrario, el enojo aparece en elevado porcentaje si se hace presente ante la perspectiva de la victoria cualquiera de los otros presidenciables: RAC (44.3\%), JAMK (56.9\%) o JRC (43.9\%). En caso de que estos no ganen las personas sentirán seguridad, también de forma mayoritaria en todos los casos: $42 \%$ si pierde RAC, $44.8 \%$ JAMK y $52.3 \%$ JRC.

3. A partir de ahora se emplearán las iniciales de los candidatos exclusivamente.

4. Las emociones fueron: miedo, enojo, seguridad, esperanza. Su elección vino dada tras aplicar varios ejercicios indagatorios previos sobre el clima emocional en esos días, así como la consulta de la prensa diaria. A la hora de procesar los datos, se tomó en cuenta también cierto porcentaje que había respondido con indiferencia. 
Tabla 3. Emociones ante el triunfo o no triunfo del candidato

\begin{tabular}{|c|c|c|c|c|c|c|c|c|}
\hline \multirow{2}{*}{ Emociones } & \multicolumn{2}{|c|}{ AMLO } & \multicolumn{2}{|c|}{ RAC } & \multicolumn{2}{|c|}{ JAMK } & \multicolumn{2}{|c|}{ JRC } \\
\hline & Gana & No gana & Gana & No gana & Gana & No gana & Gana & No gana \\
\hline Miedo & $19,5 \%$ & $14,9 \%$ & $20 \%$ & $10,4 \%$ & $22,8 \%$ & $6,5 \%$ & $33,9 \%$ & $5,9 \%$ \\
\hline Enojo & $12,1 \%$ & $49,1 \%$ & $44,3 \%$ & $22,8 \%$ & $56,9 \%$ & $14,8 \%$ & $43,9 \%$ & $13,5 \%$ \\
\hline Seguridad & $21 \%$ & $18,5 \%$ & $19,8 \%$ & $42 \%$ & $10 \%$ & $44,8 \%$ & $9,6 \%$ & $52,3 \%$ \\
\hline Esperanza & $43,9 \%$ & $13,6 \%$ & $11,8 \%$ & $20,9 \%$ & $6 \%$ & $30,4 \%$ & $8 \%$ & $24,4 \%$ \\
\hline Indiferencia & $3,3 \%$ & $3 \%$ & $4 \%$ & $3,1 \%$ & $4,1 \%$ & $3,1 \%$ & $4,4 \%$ & $3,1 \%$ \\
\hline No contestó & $0,3 \%$ & $0,9 \%$ & $0,3 \%$ & $0,9 \%$ & $0,3 \%$ & $0,8 \%$ & $0,3 \%$ & $0,9 \%$ \\
\hline Positivas & $64,9 \%$ & $32,1 \%$ & $31,6 \%$ & $62,9 \%$ & $16 \%$ & $75,2 \%$ & $17,6 \%$ & $76,7 \%$ \\
\hline Negativas & $31,6 \%$ & $64 \%$ & $64,3 \%$ & $33,2 \%$ & $79,7 \%$ & $21,3 \%$ & $77,8 \%$ & $19,4 \%$ \\
\hline
\end{tabular}

Fuente: Elaboración propia con base en los datos de la Encuesta preelectoral de la Ciudad de México, junio 2018.

Esperanza, emoción proyectada hacia un futuro de posibilidades (Bloch, 2007), forma parte de la emoción y sentimiento básico de alegría, emoción mayoritaria si triunfa AMLO. En el caso de no hacerlo aparece el enojo, emoción y sentimiento básico cuya función es la defensa y, en su caso, el enfrentamiento con algo que se considera dañino o perjudicial y que está en el presente o el pasado.

Por otra parte, si gana algún otro candidato, los participantes afirman que sentirán enojo, emoción básica y, si éstos no triunfan, lo que se sentirán en todos los casos con mayor o menor porcentaje es seguridad, sensación, emoción y sentimiento que procede del afecto, entendido éste como amor en sentido amplio (Muñoz, 2009), incluso es posible considerarla necesidad psicológica según Maslow (1982).

$\mathrm{Si}$ sumamos las emociones comentadas, entre las agradables o desagradables (comúnmente nombradas como positivas y negativas), es obvio que la mayoría de emociones positivas está en que gane AMLO y en que no ganen los demás. De ahí que aquí se hable de polarización emocional, o político-emocional, muy importante e influyente en la contienda electoral y en el ejercicio del voto ciudadano.

Según la Teoría de la inteligencia emocional (Marcus, 2002) la esperanza y el entusiasmo proporcionan confianza, contribuyen al compromiso y al apoyo. El enojo - si bien la teoría habla más de angustia - intranquiliza y conduce al no apoyo. Por otra parte, el enojo está relacionado con la indignación moral (Jasper, 2013), el agravio moral (Moore, 1985), los "marcos de la injusticia" (Snow y Gamson cit. Jasper, 2013) y con las baterías emocionales esperanza-enojo (Jasper, 2013), como emociones fuertes que energizan ambas aunque en direcciones diferentes. Emociones que tensan y movilizan a la acción de votar por alguien y de no hacerlo por otro.

Además, el enojo o la "ira noble", enfrenta la injusticia desde el compromiso, la digna indignación necesaria para la defensa de una sociedad más justa, según el enfoque cognitivoevaluativo y moral (Nussbaum, 2018). Finalmente, la seguridad, regresa a la tranquilidad y la calma de lo supuestamente conocido, la confianza (Marcus, 2002), y tal vez también a la esperanza (Bloch, 2007).

A continuación, se presenta la encuesta que ilustra extensa y cuantitativamente las emociones político-electorales y se inicia la revisión del tema a través de la riqueza de significado que proporcionan las entrevistas.

\subsection{Entrevistas}

Las "Entrevistas preelectorales" fueron realizadas en junio - unos días antes de la jornada electoral -, en total a 118 personas -47 electores de AMLO, 38 de RAC y 33 de JAMK. Se buscó que hubiera cierto porcentaje de votantes hacia determinado candidato presidencial, con el objeto de obtener más información significativa, amplia y profunda sobre las emociones en torno al mismo. Es relevante mencionar que varias preguntas estuvieron formuladas de tal manera que se pudieran cerrar a posteriori con el objeto de marcar tendencias de emociones, si bien fueron abiertas. Es decir que 
si bien la metodología es cualitativa, además de presentar transcripciones de los relatos obtenidos, antes de ellos se realizan cuadros con las tendencias emocionales de la respuesta a la pregunta en cuestión. Las "Entrevistas postelectorales" se hicieron en el mes de julio — pocos días después del día de la elección- a 127 personas - 55 votantes de
AMLO, 42 de RAC y 30 de JAMK, a estas aplican todas las características de las anteriores ${ }^{5}$. Se obtuvo la información emocional del antes y el después según la intención de voto primero y el sufragio efectuado después. El cuadro expone el resumen de las características de la muestra de las entrevistas (Tabla 4).

Tabla 4. Muestra entrevistas preelectorales y postelectorales

\begin{tabular}{ccccccccc} 
Sexo & pre & post & Edad & pre & post & Voto & $\begin{array}{c}\text { Votará } \\
\text { (pre) }\end{array}$ & Votó (post) \\
\hline Hombres & $53,39 \%$ & $54,33 \%$ & $18-34$ & $53.39 \%$ & $54.33 \%$ & AMLO & $39.83 \%$ & $43.31 \%$ \\
\hline Mujeres & $46,61 \%$ & $45,67 \%$ & $35-50$ & $27.97 \%$ & $30.71 \%$ & RAC & $32.20 \%$ & $33.07 \%$ \\
\hline & & & $51-76$ & $18.64 \%$ & $14.96 \%$ & JMK & $27.97 \%$ & $23.62 \%$
\end{tabular}

Fuente: Elaboración propia con base en la información de las Entrevistas pre y post electorales, junio y julio 2018.

\subsubsection{Entrevistas con preguntas semicerradas}

En este apartado, como ya se anunció, se revisa la información sobre las emociones y el voto hacia un candidato, gane o pierda, en la entrevista preelectoral primero y post electoral después. La información se junta en un cuadro resumen y las transcripciones la acompañan. Son varias preguntas, unas tenían opciones de respuestas - con el propósito de compararse en la medida de lo posible con la encuesta - y otras estaban totalmente abiertos. ${ }^{6}$

En los siguientes cuadros se expone: “¿qué sentiría si X gana las elecciones, elija la opción que más sienta: enojo, miedo, esperanza, seguridad?" Esto se hacía con los votantes de cada candidato en la entrevista preelectoral, y lo mismo cambiando el inicio de la pregunta por "si su candidato no gana". En la postelectoral se preguntó: ¿usted votó por: miedo, enojo, seguridad, esperanza?

En resumen, como se verá ilustrado gráficamente y con algunos relatos que enriquecen las expresiones emocionales, es posible afirmar que, para los tres candidatos según la entrevista preelectoral, que si gana AMLO y RAC los encuestados dicen sentirán esperanza y seguridad, en ese orden, y en orden inverso —para las mismas emociones - en el caso de obtener el triunfo JAMK. Es importante señalar que el mayor porcentaje de esperanza de los seguidores de AMLO. En caso de no salir victorioso su candidato los partidarios de los tres afirman que sentirán enojo y miedo, en este orden. El mayor enojo lo presentan los votantes de RAC. Luego, y con los datos de la entrevista postelectoral que solicitó identificar la emoción con la que votó cada quien, para los votantes de los tres candidatos la emoción predominante fue la esperanza - mucho más para AMLO cuyo porcentaje fue igual que el que se preveía sentirían de obtener la victoria. Es relevante señalar también que, en segundo lugar, está la seguridad a la distancia. Sin embargo, tanto para RAC como para JAMK la primera emoción fue seguridad con más de la mitad de la muestra y en segundo lugar a la distancia la esperanza, similar para ambos, así como en porcentaje comparable a la seguridad que se apuntó para el primer candidato.

De nuevo - como en la encuesta- destaca la esperanza depositada en el triunfo de AMLO, antes y después de la contienda, Iy el enojo de no obtener la victoria. También como en la encuesta aparece la seguridad tras la esperanza. ${ }^{7}$

En primer lugar, para los encuestados cuya intención de voto se inclinaba por AMLO, por tratarse de un interrogante subjetivo y de opinión, no se puede saber si finalmente votaron por el candidato, pero se tomará la respuesta como si así hubiera sido. Si bien en la entrevista postelectoral

5. En principio se iban a realizar a las mismas personas, esto no fue posible en todos los casos.

6. Si bien las primeras cuestiones se hicieron varias preguntas después de las segundas en cuanto al orden de la guía de entrevistas para no influenciar las respuestas, aquí se presentarán invertidas, pues la respuesta más cuantitativa y cerrada es más cercana a la encuesta y la cualitativa, además de ser totalmente abierta ofrece mayor diversidad de información para extenderse en la posterior explicación tras los cuadros resúmenes de tendencias elaborados con objeto de presentar de forma clara y directa la información, en ocasiones acompañada por la transcripción de testimonios.

7. Aquí se analiza candidato por candidato y se trata de entrevistas, no es posible comparar las otras emociones hacia los otros candidatos con la Aqui se analiza candidato por candidato y se trata de entrevistas, no es posible comparar las otras emociones hacia los otros candidatos
encuesta, ni el conjunto de todos. Lo comparable entre ellos son las emociones consideradas positivas si triunfan y negativas si no lo hacen. 
es una pregunta de hecho, con lo cual sí se votó por el candidato que se dijo se hizo, supuestamente ${ }^{8}$, apareció la emoción y el sentimiento de esperanza en primer lugar y de forma mayoritaria, tanto en la preelectoral (63.83\%) - el doble de hombres que de mujeres así se posicionaron- como en la postelectoral (63.64\%) (Tabla 5). La primera tarea era elegir el sentimiento que experimentaría si ganaba y la segunda era identificar el sentimiento a la hora de votar. En segundo lugar aparece la seguridad, para ambas entrevistas, con un $12.77 \%$ en la primera y $16.36 \%$ en la segunda. El cuadro muestra el total de respuestas para tener el panorama completo.

Tabla 5. Emociones se gana o no gana y al votar por el candidato

\section{Votantes de AMLO}

¿Qué sentirá si AMLO gana las elecciones, elija la que más sienta: enojo, miedo, esperanza, seguridad?
Si AMLO no gana las elecciones ¿cómo se sentirá, elija una emoción: enojo, miedo, esperanza y seguridad?
¿Usted votó por: miedo, enojo, seguridad, esperanza?

\begin{tabular}{|c|c|c|c|c|c|c|c|c|c|c|c|c|c|c|}
\hline & $\mathrm{H}$ & $\mathrm{M}$ & & Total & & $\mathrm{H}$ & M & & Total & & $\mathrm{H}$ & M & & Total \\
\hline & $\mathrm{n}$ & $\mathrm{n}$ & $\mathrm{n}$ & $\%$ & & $\mathrm{n}$ & $\mathrm{n}$ & $\mathrm{n}$ & $\%$ & & $\mathrm{n}$ & $\mathrm{n}$ & $\mathrm{n}$ & $\%$ \\
\hline Esperanza & 20 & 10 & 30 & $63.83 \%$ & Enojo & 8 & 10 & 18 & $38.30 \%$ & Esperanza & 17 & 18 & 35 & $63.64 \%$ \\
\hline Seguridad & 3 & 3 & 6 & $12.77 \%$ & Miedo & 11 & 4 & 15 & $31.91 \%$ & Seguridad & 6 & 3 & 9 & $16.36 \%$ \\
\hline Miedo & 2 & 0 & 2 & $4.26 \%$ & Esperanza & 1 & 1 & 2 & $4.26 \%$ & Miedo & 1 & 1 & 2 & $3.64 \%$ \\
\hline Enojo & 0 & 0 & 0 & $0.00 \%$ & Seguridad & 1 & 0 & 1 & $2.13 \%$ & Enojo & 0 & 1 & 1 & $1.82 \%$ \\
\hline Otro & 4 & 3 & 7 & $14.89 \%$ & Otro & 7 & 2 & 9 & $19.15 \%$ & Otro & 4 & 1 & 5 & $9.09 \%$ \\
\hline No contestó & 0 & 2 & 2 & $4.26 \%$ & $\begin{array}{l}\text { No sabe/No } \\
\text { contestó }\end{array}$ & 1 & 1 & 2 & $4.26 \%$ & No contestó & 2 & 1 & 3 & $5.45 \%$ \\
\hline Total & 29 & 18 & 47 & $100 \%$ & Total & 29 & 18 & 47 & $100 \%$ & Total & 30 & 25 & 55 & $100 \%$ \\
\hline
\end{tabular}

Fuente: Elaboración propia con base en la información de las Entrevistas pre y post electorales. H- Hombres $M$ - Mujeres

También, en la entrevista preelectoral, se interrogó sobre lo que sentirian los votantes si no ganaba su candidato, el enojo se posicionó con un $38.30 \%$ en primer lugar, seguido por el miedo (31.91\%) en segundo. Así, si gana como ganó el candidato hay esperanza —que es una emoción futura y que se basa en la básica de alegría- Y en caso de no ganar, hipotéticamente hablando, el enojo y el miedo serían las emociones que se consideraría se sentirían.

En las preguntas preelectorales se solicitaba, en el mismo enunciado, elegir una opción, por lo cual apenas hubo comentarios más allá de la palabra-emoción como respuesta. Sin embargo, en el interrogante post electoral, que era más abierto, junto a la emoción se daba una suerte de explicación sobre la misma, algunas de las cuales traemos a estas páginas.

Entre los electores de AMLO, junto a la emoción de esperanza, una joven de 19 años dijo:

"El único sentimiento que hubo y existió en mí en ese momento fue esperanza y felicidad, porque estaba haciendo valer mi voto. Entre todos íbamos a tomar la mejor decisión y camino, para que nuestro país y nosotros mismos tuviéramos otra oportunidad de ser mejores".

"Voté con esperanza de que fuera una buena opción" (hombre 20 años), "por esperanza porque ya estoy harto de Peña" (hombre 22 años), "esperanza, porque me gusta pensar que las cosas pueden cambiar para bien" (mujer 23 años), "por esperanza de que se ayude a los sectores que se han comprometido a ayudar" (mujer 23 años), "sentí la posibilidad que después de tantos años, al fin se produjera un cambio importante gracias al voto de la gente" (mujer 28 años), "esperanza e ilusión de ver a AMLO como presidente, a ver si cumple con sus promesas" (mujer 35 años), "Esperanza, porque sinceramente votar por el PRI y PAN sería más de lo mismo" (mujer 44 años), "esperanza y por un verdadero cambio, no sé si AMLO cumpla todo lo que prometió, pero tendrá que tener en cuenta que el primero de julio se hizo historia, no solo porque después de tantos años consiguió el

8. Esto aplica para todos los candidatos en las diversas preguntas. 
triunfo, sino por toda la gente que salió en su apoyo, el compromiso con el pueblo es mayor" (hombre 25 años), "Esperanza, porque siento que este presidente si nos quiere" (hombre 48 años), "Por esperanza, porque yo quiero ser parte del cambio" (hombre 48 años).

Todos estos testimonios recuerdan las emociones compartidas y recíprocas, el entusiasmo de compartir un proyecto, la identidad colectiva de pertenecer a algo importante, los lazos afectivos, y la "sensación de estar haciendo historia" (Jasper, 2013).

"Más que por esperanza fue por la unión popular, por el compromiso con los demás y hacer caso al llamado. No fue tanto por esperanza. No es algo que esperas, no te sientas a esperar por la esperanza. No sentía esperanza en AMLO en sí, tenía la esperanza de que la decisión popular se respetara" (hombre 26 años). La esperanza es entendida aquí no como espera pasiva, desesperanza o ideal romántico inalcanzable, sino como elemento donde se despliega la confianza ante la posibilidad de lo nuevo, frente a lo que todavía no nace, disposición interna a actuar en post del cambio (Fromm, 1984).

Tras la enunciación de la sensaciónemoción de seguridad hubo quien añadió: “de poder cambiar mi país con mi voto" (hombre 20 años), "porque sabía que ese candidato tiene una buena trayectoria" (hombre 21 años). Lealtades afectivas, apegos emocionales, entre líder y electores, evaluación y valoración moral (Nussbaum, 2012).

Finalmente, en este caso que estudia solo a los votantes de AMLO, los resultados de las entrevistas pre y post electorales son contrastables, en cuanto a tendencia, con los que se registraron en la encuesta preelectoral, salvando la distancia de lo cuantitativo y cualitativo, lo no comparable en este sentido, y teniendo en cuenta también las diferencias porcentuales de los resultados en los tres ejercicios comentados.

No obstante, se reitera, el triunfo que AMLO en las dos entrevistas produce esperanza, lo mismo que su victoria según la encuesta. La esperanza cobra una relevancia cuantitativa y cualitativa importante. Por otra parte, y según la entrevista preelectoral y la encuesta también preelectoral, de no ganar los encuestados afirman que sentirán enojo por lo que aquí interesa destacar que ambas fuentes apuntaban en la misma dirección y se refuerza la idea de esta batería moral (Jasper, 2013) entre esperanza y enojo, que al parecer tuvo lugar en la elección.

Tabla 6. Emociones si gana o no gana y al votar por el candidato

Votantes de RAC

¿Qué sentirá si RAC gana las elecciones, elija la que más sienta: enojo, miedo, esperanza, seguridad?
Si RAC no gana las elecciones ¿cómo se sentirá, elija una emoción: enojo, miedo, esperanza y seguridad?
¿Usted votó por: miedo, enojo, seguridad, esperanza?

\begin{tabular}{|c|c|c|c|c|c|c|c|c|c|c|c|c|c|c|}
\hline & $\mathrm{H}$ & $\mathrm{M}$ & & Total & & $\mathrm{H}$ & M & & Total & & $\mathrm{H}$ & M & & Total \\
\hline & $\mathrm{n}$ & $\mathrm{n}$ & $\mathrm{n}$ & $\%$ & & $\mathrm{n}$ & $\mathrm{n}$ & $\mathrm{n}$ & $\%$ & & $\mathrm{n}$ & $\mathrm{n}$ & $\mathrm{n}$ & $\%$ \\
\hline Esperanza & 8 & 12 & 20 & $52.63 \%$ & Enojo & 5 & 13 & 18 & $47.37 \%$ & Seguridad & 13 & 10 & 23 & $54.76 \%$ \\
\hline Seguridad & 5 & 9 & 14 & $36.84 \%$ & Miedo & 5 & 6 & 11 & $28.95 \%$ & Esperanza & 3 & 4 & 7 & $16.67 \%$ \\
\hline Miedo & 0 & 1 & 1 & $2.63 \%$ & Esperanza & 2 & 0 & 2 & $5.26 \%$ & Enojo & 0 & 3 & 3 & $7.14 \%$ \\
\hline Enojo & 0 & 0 & 0 & $0.00 \%$ & Seguridad & 0 & 0 & 0 & $0.00 \%$ & Miedo & 0 & 2 & 2 & $4.76 \%$ \\
\hline Otro & 2 & 0 & 2 & $5.26 \%$ & Otro & 4 & 1 & 5 & $13.16 \%$ & Otro & 4 & 1 & 5 & $11.90 \%$ \\
\hline $\begin{array}{l}\text { No sabe/No } \\
\text { contestó }\end{array}$ & 1 & 0 & 1 & $2.63 \%$ & $\begin{array}{l}\text { No sabe/No } \\
\text { contestó }\end{array}$ & 0 & 2 & 2 & $5.26 \%$ & No contestó & 0 & 2 & 2 & $4.76 \%$ \\
\hline Total & 16 & 22 & 38 & $100 \%$ & Total & 16 & 22 & 38 & $100 \%$ & Total & 20 & 22 & 42 & $100 \%$ \\
\hline
\end{tabular}

Fuente: Elaboración propia con base en los datos de las Entrevistas pre y post electorales. H-Hombres M- Mujeres

Lo que sentirían los electores de RAC si gana o no gana las votaciones y con qué emoción lo votaron sus electores, se puede resumir en esperanza (52.63\%) y seguridad $(36.84 \%$, según la entrevista preelectoral en el caso de ganar. Con base en esta misma fuente, si perdiera, sentirian enojo $(47.37 \%)$ y miedo (28.95\%) —más mujeres que hombres-. Finalmente, en el momento de votar dijeron haberlo hecho guiados por la seguridad $(54.76 \%)$ y la esperanza (16.67\%) (Tabla 6).

La seguridad a la hora de sufragar se vivenció así: "Seguridad, por mantener nuestra economía" (hombre 20 años), "Por seguridad porque las propuestas del candidato me daban 
confianza" (mujer 20 años), "porque creía que era la mejor opción" (mujer 22 años), "Por seguridad sin duda, porque representaba y tenía todo lo necesario para conducir al país, su intelecto era evidente y brillante, recuerde cómo se desempeñó en los debates" (mujer 43 años), "Seguridad, porque creo que él era el más preparado" (mujer 47 años), "voté por seguridad de conservar lo que tengo y pues por el progreso" (hombre 59 años). Esta seguridad quizás es asimilable a tranquilidad y confianza según el sistema de disposición afectiva (Marcus, 2002).

En cuanto a la esperanza los votantes se manifestaron así: "Esperanza, porque creía que era la mejor opción para el futuro para México" (mujer 19 años), "Por esperanza: porque la situación del país, en general está muy mal y necesitamos cambiarla” (mujer 20 años).

En ocasiones ambas emociones estuvieron presentes: "Seguridad porque sabía que Anaya estaba muy preparado y esperanza porque quería que ganara" (hombre 22 años), "Seguridad y esperanza para que el país mejorará con el cambio de presidente" (mujer 24 años), "Seguridad en mî mismo por mis responsabilidades de ciudadano y esperanza de ser un mejor país” (hombre 36 años). Necesidades y emociones conjuntadas.

Tabla 7. Emociones si gana o no gana y al votar por el candidato

Votantes de JAMK

¿Qué sentirá si JAMK gana las elecciones, elija la que más sienta: enojo, miedo, esperanza, seguridad?
Si JAMK no gana las elecciones ; cómo se sentirá, elija una emoción: enojo, miedo, esperanza y seguridad?
¿Usted votó por: miedo, enojo, seguridad, esperanza?

\begin{tabular}{|c|c|c|c|c|c|c|c|c|c|c|c|c|c|c|}
\hline & $\mathrm{H}$ & M & & Total & & $\mathrm{H}$ & M & & Total & & $\mathrm{H}$ & M & & Total \\
\hline & $\mathrm{n}$ & $\mathrm{n}$ & $\mathrm{n}$ & $\%$ & & $\mathrm{n}$ & $\mathrm{n}$ & $\mathrm{n}$ & $\%$ & & $\mathrm{n}$ & $\mathrm{n}$ & $\mathrm{n}$ & $\%$ \\
\hline Seguridad & 9 & 4 & 13 & $39.39 \%$ & Enojo & 4 & 7 & 11 & $33.33 \%$ & Seguridad & 11 & 5 & 16 & $53.33 \%$ \\
\hline Esperanza & 2 & 8 & 10 & $30.30 \%$ & Miedo & 4 & 1 & 5 & $15.15 \%$ & Esperanza & 3 & 2 & 5 & $16.67 \%$ \\
\hline Enojo & 0 & 1 & 1 & $3.03 \%$ & Seguridad & 1 & 2 & 3 & $9.09 \%$ & Miedo & 1 & 0 & 1 & $3.33 \%$ \\
\hline Miedo & 0 & 0 & 0 & $0.00 \%$ & Esperanza & 0 & 1 & 1 & $3.03 \%$ & Enojo & 1 & 0 & 1 & $3.33 \%$ \\
\hline Otro & 5 & 2 & 7 & $21.21 \%$ & Otro & 6 & 3 & 9 & $27.27 \%$ & Otro & 3 & 3 & 6 & $20.00 \%$ \\
\hline $\begin{array}{l}\text { No sabe/No } \\
\text { contestó }\end{array}$ & 2 & 0 & 2 & $6.06 \%$ & $\begin{array}{l}\text { No sabe/No } \\
\text { contestó }\end{array}$ & 3 & 1 & 4 & $12.12 \%$ & No contestó & 0 & 1 & 1 & $3.33 \%$ \\
\hline Total & 18 & 15 & 33 & $100 \%$ & Total & 18 & 15 & 33 & $100 \%$ & Total & 19 & 11 & 30 & $100 \%$ \\
\hline
\end{tabular}

Fuente: Elaboración propia con base en los datos de las Entrevistas pre y post electorales.

Ahora veamos las emociones declaradas de las y los votantes de JAMK. Para empezar, en la preelectoral dijeron que, si ganaba su candidato las elecciones, sentirían seguridad (39.39\%) más hombres que mujeres-y esperanza (30.30\%) -más mujeres que hombres-. Si su candidato perdía sentirían 33.33\% enojo y $15.15 \%$ miedo, por mencionar las más nombradas. Tras la elección afirmaron que al votar lo hicieron con seguridad (53.33\%) en primer lugar y con esperanza (16.67\%) en segundo (Tabla 7).

Respecto a estas dos últimas emociones, quienes remarcaron la seguridad esto fue por "un ideal, una transformación coherente en el país que sí promete progreso. No por las utopías de un viejito" (hombre 19 años), "Por certidumbre política, social y económica” (hombre 19 años), "Seguridad, porque pensé que con Meade podríamos hacer cosas buenas" (hombre 26 años), "seguridad porque un candidato bien preparado académicamente quiere decir que está preparado para el puesto, pero AMLO no está muy preparado académicamente y me da miedo que vaya a hacer una tontería” (hombre 35 años), "Seguridad, porque conozco al PRI y sé cómo puede gobernar" (hombre 68 años). Seguridad en el sentido de calma y confianza, continuidad, todo según el sistema de disposición afectiva (Marcus, 2002).

Aquellas personas que subrayaron sentir esperanza lo justificaron así: "Esperanza, de hacer que alguien que fuera coherente y estuviera capacitado fuera a ser presidente" (mujer 22 años), "Mucha esperanza de que las cosas siguieran mejorando" (hombre 45 años).

\subsubsection{Entrevistas con preguntas totalmente abiertas}

Aquí se analizan los cuadros que se extraen de una pregunta abierta sobre los sentimientos y emociones de los votantes si los candidatos ganaban o perdían la presidencia. Esta pregunta era totalmente abierta, a diferencia de la anterior que solicitaba elegir entre 
algunas opciones de respuestas predeterminadas y explicarlas. La preguntas eran: “¿sí X gana la presidencia cómo se sentirá usted?” Y también “¿Si $\mathrm{X}$ no gana la presidencia cómo se sentirá usted?” Esto en la entrevista preelectoral.

En la entrevista postelectoral la pregunta obligada, una vez conocidos los resultados de las elecciones, era: ¿Cómo se siente que haya ganado AMLO? en el caso del ganador, y en los otros casos: ¿Cómo se siente que no haya ganado RAC o JAMK? Se pregunta por grupos de votantes de cada líder político, hay gran diversidad y amplitud de respuestas, por lo que se recogen las tendencias en cuadros y luego se ilustran en una selección de testimonios.

A grandes rasgos queda clara la felicidad y alegría por el triunfo de AMLO, antes y después de la elección, aquí recogida por la entrevista preelectoral y la postelectoral. Además, se reconoce una gama de emociones, unas más numerosas que otras, alguna incertidumbre antes que se desdibuja después, y el aviso del enojo y decepción en caso hipotético que no ganara, como se observa en la respuesta a ese cuestionamiento en la preelectoral.

Por otra parte, y como parece lógico, los otros dos candidatos, recogen también alegría y felicidad, así como satisfacción, entre otras cosas, ante la posibilidad de triunfo. y se apunta la decepción y desilusión en ambos, incluso miedo en los votantes de RAC, y enojo en los dos casos si sus candidatos no obtuvieran el triunfo, emociones que se confirman ya en la postelectoral cuando presentan decepción en los electores de ambos, así como enojo en diferente medida - más en los de JAMK-, además de tristeza entre los de RAC e incertidumbre en los de JAMK. La riqueza de la diversidad emocional se recoge en los cuadros correspondientes y en las transcripciones de los testimonios.

Sobre estas emociones, algunas ya comentadas con anterioridad, solo falta señalar la relación entre incertidumbre y miedo, que provienen de diversas causas como se muestra en los relatos. La decepción y la desilusión tienen que ver sobre todo con la emoción básica de tristeza, que invita a la retirada, a la introspección y desalienta. La satisfacción aquí la entendemos como sentirse bien, cierto estado de ánimo equilibrado y tranquilo, o también puede considerarse como la satisfacción ante la acción para la obtención de la necesidad o deseo cumplido (Maslow, 1982; Muñoz, 2009).

Tabla 8. Emociones si gana o no gana y al haber ganado el candidato

Votantes de AMLO

\begin{tabular}{|c|c|c|c|c|c|c|c|c|c|c|c|c|c|c|}
\hline \multicolumn{5}{|c|}{$\begin{array}{l}\text { ¿Si AMLO gana la presidencia } \\
\text { cómo se sentiría usted? }\end{array}$} & \multicolumn{5}{|c|}{$\begin{array}{l}\text { ¿Si AMLO no gana la presidencia } \\
\text { cómo se sentiría usted? }\end{array}$} & \multicolumn{5}{|c|}{$\begin{array}{c}\text { ¿Cómo se siente que haya ganado } \\
\text { AMLO? }\end{array}$} \\
\hline \multirow{4}{*}{$\begin{array}{l}\text { Felicidad/ } \\
\text { Alegre/ Contento } \\
\text { Expectativa/ } \\
\text { Incertidumbre/ } \\
\text { Angustia/ } \\
\text { Ansiedad/ } \\
\text { Curiosidad }\end{array}$} & $\mathrm{H}$ & M & & Total & & $\mathrm{H}$ & $\mathrm{M}$ & & Total & & $\mathrm{H}$ & $\mathrm{M}$ & & Total \\
\hline & $\mathrm{n}$ & $\mathrm{n}$ & $\mathrm{n}$ & $\%$ & & $\mathrm{n}$ & $\mathrm{n}$ & $\mathrm{n}$ & $\%$ & & $\mathrm{n}$ & $\mathrm{n}$ & $\mathrm{n}$ & $\%$ \\
\hline & 13 & 4 & 17 & 36.17 & $\begin{array}{l}\text { Enojado/ } \\
\text { Frustración/ } \\
\text { Inconforme }\end{array}$ & 10 & 3 & 13 & 27.66 & $\begin{array}{l}\text { Feliz/Alegre/ } \\
\text { Emocionado }\end{array}$ & 16 & 12 & 28 & 50.91 \\
\hline & 5 & 4 & 9 & 19.15 & $\begin{array}{l}\text { Decepcionado/ } \\
\text { Defraudado/ } \\
\text { Desilusionado }\end{array}$ & 4 & 3 & 7 & 14.89 & $\begin{array}{l}\text { Bien/ Satisfac- } \\
\text { ción/ Alivio }\end{array}$ & 5 & 8 & 13 & 23.64 \\
\hline $\begin{array}{l}\text { Bien/De } \\
\text { maravilla/ } \\
\text { Satisfecho }\end{array}$ & 6 & 2 & 8 & 17.02 & $\begin{array}{l}\text { Expectativa/ } \\
\text { Incertidumbre/ } \\
\text { Miedo/ Temero- } \\
\text { so/ Preocupación }\end{array}$ & 4 & 2 & 6 & 12.77 & Esperanza & 1 & 4 & 5 & 9.09 \\
\hline $\begin{array}{l}\text { Tranquilo/ } \\
\text { Conforme/ } \\
\text { Aliviado }\end{array}$ & 2 & 6 & 8 & 17.02 & Triste & 3 & 2 & 5 & 10.64 & $\begin{array}{l}\text { Expectante/ } \\
\text { Ilusión }\end{array}$ & 4 & 0 & 4 & 7.27 \\
\hline $\begin{array}{l}\text { Esperanzado/ } \\
\text { Entusiasmado }\end{array}$ & 2 & 0 & 2 & 4.26 & Indiferente & 2 & 3 & 5 & 10.64 & Comprometido & 1 & 0 & 1 & 1.82 \\
\hline Seguro & 1 & 0 & 1 & 2.13 & Fatal/Mal & 1 & 2 & 3 & 6.38 & Nada & 1 & 0 & 1 & 1.82 \\
\hline Sorpresa & 0 & 1 & 1 & 2.13 & $\begin{array}{l}\text { Desconfiado/ } \\
\text { Inseguridad }\end{array}$ & 2 & 1 & 3 & 6.38 & Estupefacto & 0 & 1 & 1 & 1.82 \\
\hline No contestó & 0 & 1 & 1 & 2.13 & Bien & 1 & 0 & 1 & 2.13 & No contestó & 2 & 0 & 2 & 3.64 \\
\hline \multirow[t]{3}{*}{ Total } & 29 & 18 & 47 & 100 & Dolido & 1 & 0 & 1 & 2.13 & Total & 30 & 25 & 55 & 100 \\
\hline & & & & & No contestó & 1 & 2 & 3 & 6.38 & & & & & \\
\hline & & & & & Total & 29 & 18 & 47 & 100 & & & & & \\
\hline
\end{tabular}

Fuente: Elaboración propia con base en los datos de las Entrevistas pre y post electorales. 
Para los seguidores de AMLO en la entrevista preelectoral, si éste obtiene el triunfo, la emoción será $36.17 \%$ de felicidad-alegría, $19.15 \%$ de incertidumbre y angustia, $17.02 \%$ de bien y satisfacción, y otro porcentaje igual de tranquilo y aliviado (Tabla 8). Parecen emociones contradictorias, pero las narraciones posteriores lo aclararán.

Algunos comentarios sobre el tema entre quienes dijeron sentirían alegría-felicidad fueron: "cuando gane sentiré felicidad total, esperanza, euforia" (hombre 21 años), "Feliz, porque por primera vez, ganaría alguien por quien yo voté” (hombre 22 años), "Feliz, ganamos y todo será mejor" (hombre 46 años), "Feliz y no solo por mí, sino por México “ (mujer 40 años), "Felicidad, por mi familia y creo que por todo el país" (hombre 49 años). Felicidad social compartida y extendida.

Los que señalaron sentirían incertidumbre y angustia comentaron: "ansioso... Tal vez, también preocupado" (hombre 22 años), "Con mucha angustia, esperando que cumpla” (mujer 23 años), "Me sentiré con la incertidumbre de pensar en el "que pasará”, ya que ninguno es confiable" (hombre 30 años). En general, un nerviosismo multicausal.

Quienes dicen sentirse bien y satisfechos comentaron: "bien, contento, por fin se va a poder hacer una fiesta nacional y salir a las calles y decir al fin se pudo conseguir algo, algo cambió, algo se logró" (hombre 26 años), "Bien y con esperanza de que todo se ponga mejor en el país” (mujer 39 años), "Bien, porque le estaríamos ganando a toda la gente mala que gobierna a este país y mejorar la cosas" (mujer 43 años).

Los que estarían tranquilos y aliviados, "Me sentiré muy tranquila" (mujer 22 años), "será un gran alivio para el país” (mujer 30 años).

Quienes sintieron un conjunto de emociones concatenadas: "me sentiría un poco aliviado y con un poco de felicidad, tranquilidad" (hombre 21), "Tal vez contenta o tal vez me lleve una desilusión después” (mujer 69 años).

Para la misma pregunta en la misma entrevista pero en el caso de no ganar el candidato: $27.66 \%$ dice que se sentirá enojado-frustrado, 14.89\% decepcionado - desilusionado, 12.77\% sentirá incertidumbre-miedo, algunos también dijeron triste, y otros, indiferente.

Sobre enojado y frustrado lo participantes dijeron: "enojada, porque aparentemente AMLO es el que va ganando, si así tan de pronto hay un cambio es porque ya hubo corrupción o compra de votos" (mujer 20 años), "Definitivamente enfadado, timado hasta embaucado, han pasado muchos años y siempre nos han gobernado los mismos" (hombre 22 años), "Me sentía muy frustrado como enojado más que nunca por las encuestas, el fraude sería muy evidente como en el 2006, en el 2012, nulo respeto a la democracia” (hombre 26 años), "Enojo y hambre de lucha y justicia” (hombre 46 años). Enojo, indignado, contra la injusticia (Nussbaum, 2018).

En torno a la decepción y la desilusión dijeron: "decepcionado y defraudado por el sistema electoral” (hombre 30 años), “decepcionada de las instituciones en México” (mujer 30 años). Al respecto de los que apuntaron miedo e incertidumbre: "incertidumbre de no saber qué nos depara a futuro" (hombre 30 años). Y la suma de varias: "Si de manera hipotética no ganara, pues tristeza, incertidumbre, miedo de lo que llegue a pasar los próximos" (hombre 21 años).

Tras las elecciones, en la entrevista la emoción sobresaliente con la mitad de la muestra entrevistada (50.91\%) fue felicidad-alegría, 23.64\% bien y satisfacción y 9.09\% esperanza. Todo en concordancia con la pregunta de la entrevista anterior y la encuesta.

Quienes se sintieron alegres y felices ante la victoria de AMLO, señalaron: "muy feliz, siento que mi voto por fin es tomado en cuenta" (hombre 20 años), "Me siento alegre que alguien que ha tenido historia en la lucha social haya logrado su cometido, ya había sido candidato anteriormente, pero ahora fue en el momento oportuno, es una persona que en serio quiere cambiar las cosas en el país" (hombre 22 años), "Feliz y con la esperanza de que México cambie para bien de nuestra sociedad" (hombre 30 años), "Muy feliz y con ganas de ver el cambio” (mujer 35 años), "Muy feliz, es un resultado que venía esperando desde hace 12 años" (hombre 43 años), "Me siento feliz de que haya ganado, sé que él de verdad nos representa y sabrá tomar las mejores decisiones en beneficio de todos" (mujer 55 años). En términos globales los sentimientos son de felicidad con confianza, esperanza y entusiasmo.

Quienes se sintieron bien y satisfechos comentaron: "bien por saber que mi decisión se respetó y se dejó ver unas elecciones transparentes" (hombre 22 años), "Me siento satisfecha de que no se haya hecho fraude...Que la gente haya salido a votar como lo hizo fue lo que más me hizo feliz, más allá del resultado" (mujer 23 años). 
Y quienes expresaron esperanza afirmaron: "con mucha esperanza de saber qué pasará o que hará para cumplir sus promesas de campaña" (mujer 30 años), "Pues con mucha esperanza de que él sí pueda cambiar al país" (mujer 44 años),
"Esperanzada de que cumpla lo que prometió" (mujer 46 años). Sentimientos morales bajo las emociones políticas (Jasper, 2013; Nussbaum, 2011).

Tabla 9. Emociones si gana o no gana y al no haber ganado el candidato

Votantes de RAC

\begin{tabular}{|c|c|c|c|c|c|c|c|c|c|c|c|c|c|c|}
\hline \multicolumn{5}{|c|}{$\begin{array}{l}\text { ¿Si RAC gana la presidencia cómo se } \\
\text { sentiría usted? }\end{array}$} & \multicolumn{5}{|c|}{$\begin{array}{l}\text { ¿Si RAC no gana la presidencia cómo se } \\
\text { sentiría usted? }\end{array}$} & \multicolumn{5}{|c|}{$\begin{array}{c}\text { ¿Cómo se siente de que no haya ganado } \\
\text { RAC? }\end{array}$} \\
\hline & $\mathrm{H}$ & M & & Total & & $\mathrm{H}$ & M & & Total & & $\mathrm{H}$ & M & & Total \\
\hline & $\mathrm{n}$ & $\mathrm{n}$ & $\mathrm{n}$ & $\%$ & & $\mathrm{n}$ & $\mathrm{n}$ & $\mathrm{n}$ & $\%$ & & $\mathrm{n}$ & $\mathrm{n}$ & $\mathrm{n}$ & $\%$ \\
\hline $\begin{array}{l}\text { Alegre/Feliz/ } \\
\text { Contento }\end{array}$ & 5 & 8 & 13 & 34.21 & $\begin{array}{l}\text { Desilusionado } \\
\text { Decepcionado/ } \\
\text { Defraudado }\end{array}$ & 2 & 9 & 11 & 28.95 & $\begin{array}{l}\text { Decepción/ } \\
\text { Desilusión }\end{array}$ & 7 & 5 & 12 & 28.57 \\
\hline $\begin{array}{l}\text { Bien/Muy bien/ } \\
\text { Satisfecho }\end{array}$ & 4 & 6 & 10 & 26.32 & $\begin{array}{l}\text { Preocupación/ } \\
\text { Miedo/ } \\
\text { Incertidumbre/ } \\
\text { Expectativa }\end{array}$ & 6 & 3 & 9 & 23.68 & Triste & 4 & 3 & 7 & 16.67 \\
\hline $\begin{array}{l}\text { Esperanzado/ } \\
\text { Animado/ } \\
\text { Participativo }\end{array}$ & 3 & 2 & 5 & 13.16 & $\begin{array}{l}\text { Enojado/ } \\
\text { Molesto/ } \\
\text { Frustrado }\end{array}$ & 3 & 2 & 5 & 13.16 & $\begin{array}{l}\text { Enojo/ } \\
\text { Frustración }\end{array}$ & 4 & 2 & 6 & 14.29 \\
\hline Indiferente & 1 & 2 & 3 & 7.89 & Triste & 0 & 3 & 3 & 7.89 & $\begin{array}{l}\text { Preocupación/ } \\
\text { Miedo/ } \\
\text { Incertidumbre }\end{array}$ & 0 & 4 & 4 & 9.52 \\
\hline $\begin{array}{l}\text { Tranquilo/ } \\
\text { Aliviado }\end{array}$ & 1 & 2 & 3 & 7.89 & Igual/Normal & 1 & 1 & 2 & 5.26 & Mal & 2 & 1 & 3 & 7.14 \\
\hline Derrotado & 1 & 0 & 1 & 2.63 & $\begin{array}{l}\text { Desesperanza/ } \\
\text { Desanimado }\end{array}$ & 1 & 1 & 2 & 5.26 & $\begin{array}{l}\text { Bien/ } \\
\text { Satisfacción }\end{array}$ & 1 & 1 & 2 & 4.76 \\
\hline Incertidumbre & 0 & 1 & 1 & 2.63 & Confianza & 1 & 0 & 1 & 2.63 & Resignación & 0 & 2 & 2 & 4.76 \\
\hline No contestó & 1 & 1 & 2 & 5.26 & Incredulidad & 1 & 0 & 1 & 2.63 & $\begin{array}{l}\text { Sorpresa/ } \\
\text { Confusión }\end{array}$ & 1 & 1 & 2 & 4.76 \\
\hline \multirow[t]{5}{*}{ Total } & 16 & 22 & 38 & 100 & Mal & 0 & 1 & 1 & 2.63 & Indiferente & 1 & 0 & 1 & 2.38 \\
\hline & & & & & Sorprendido & 0 & 1 & 1 & 2.63 & Confianza & 0 & 1 & 1 & 2.38 \\
\hline & & & & & Aceptación & 0 & 1 & 1 & 2.63 & Feliz & 0 & 1 & 1 & 2.38 \\
\hline & & & & & No contestó & 1 & 0 & 1 & 2.63 & Normal & 0 & 1 & 1 & 2.38 \\
\hline & & & & & Total & 16 & 22 & 38 & 100 & Total & 20 & 22 & 42 & 100 \\
\hline
\end{tabular}

Fuente: Elaboración propia con base en los datos de las Entrevistas pre y post electorales.

Los que afirmaron que votarian primero, luego haber votado por RAC, en primer momento dijeron que se sentirían alegres-felices si ganaba $34.21 \%$, bien y satisfechos $26.32 \%$, y $13.16 \%$ esperanzado (Tabla 9).

Los alegres y felices comentaron: "feliz de que terminará el poder del PRI” (mujer 30 años), "Muy feliz, porque ganaría el candidato por quien yo voté, muy feliz por mí y por México" (mujer 45 años).

Guienes se sintieron bien y satisfechos dijeron: "No me sentiré feliz, pero me sentiré bien de que no gane Obrador" (mujer 21 años), "Satisfecho y con esperanzas de que cumpla lo que dijo" (hombre 22 años), "Satisfecha de que mi voto contribuyó a que ganara el candidato de mi preferencia" (mujer 39 años), "Bien si lleva a cabo todo lo que dijo" (hombre 70 años). Los esperanzados por su parte afirmaron: "con esperanza de que el país mejor" (hombre 24 años). Como se observa, y llama la atención, algunos dijeron feliz y bien pero en el caso de que no ganase AMLO o de que el PRI salga del gobierno, más que por el triunfo de su candidato.

En la misma entrevista, pero a la pregunta del sentimiento que experimentarían si no ganaba la presidencia el candidato, se sentirían decepcionados-desilusionados en primer lugar (28.95\%), con miedo e incertidumbre (23.68\%), y en enojados y frustrados (13.16\%).

Quienes afirmaron que sentirian decepción y desilusión dijeron: "Decepcionada del proceso de democracia" (mujer 24 años), "Desilusionado, porque no quedó el candidato con mejores propuestas y mayor preparación” (hombre 42 años), "Pues no enojada, decepcionada de que pues de que tal vez el que venga no haga las cosas bien" (mujer 47 años).

Para quienes el miedo, la incertidumbre y la preocupación era predominante los comentarios 
fueron: "muy preocupada porque es obvio que si no es Anaya es Obrador entonces me daría mucha incertidumbre de lo que haga" (mujer 21 años). Con enojo y frustración: "enojada y frustrada" (mujer 50 años).

En la entrevista posterior a la elección y ante la derrota de este candidato, sus votantes dijeron sentir decepción (28.57\%), tristeza (16.67\%) y enojo (14.29\%).

La decepción la expresaron así: "decepcionado de que no se haya elegido la mejor opción" (hombre 19 años), "Me desilusiona que el país tome decisiones por fanatismo más que por la razón” (mujer 20 años), "la verdad decepcionado... y preocupado de que ganara Obrador" (hombre 28 años). A veces junto a la tristeza: "Triste, yo creo que era una buena opción para el país" (mujer 20 años), "Triste y con decepción" (hombre 27 años), "Muy triste y decepcionada" (mujer 43 años).

El enojo fue acompañado de las siguientes citas: "me siento muy enojada porque ganó la ignorancia y el conformismo" (mujer 20 años), "Pues con un poco de enojo, espero que el pueblo no se haya equivocado con la decisión que se tomó" (hombre 47 años), "Enojo, porque cómo es posible que la gente vote por alguien asî” (hombre 70 años).

Además, quienes expresaron miedo dijeron: "me siento preocupada de que es lo que va a pasar con el país habiendo ganado Obrador, por sus ideas izquierdistas" (mujer 58 años), "pues siento miedo de que vayamos a estar como Venezuela, enojo de que haya ganado alguien que no tiene idea de cómo va a hacer lo que tanto promete" (mujer 59 años). Varias emociones eran causadas por el triunfo de AMLO.

Las emociones van cambiando y los encuestados llegan a afirmar: "pues al principio sentí mucha incertidumbre, sin embargo, veo que la gente se muestra positiva ante este cambio entonces a lo mejor esa emoción a la gente puede ocasionarles un cambió de actitud o eso esperaría" (mujer 31 años), "Decepcionada, porque ganó todo lo contrario que le hace falta al país, pero esperemos que el señor Obrador desempeñe un buen papel" (mujer 40 años).

Tabla 10. Emociones si gana o no gana y al no haber ganado el candidato

Votantes de JAMK

¿Si JAMK gana la presidencia cómo se sentiría usted?

\begin{tabular}{cccc}
$\mathrm{H}$ & $\mathrm{M}$ & & Total \\
$\mathrm{n}$ & $\mathrm{n}$ & $\mathrm{n}$ & $\%$ \\
\hline
\end{tabular}

\begin{tabular}{|c|c|c|c|c|c|c|c|c|c|c|c|c|c|c|}
\hline & $\mathrm{n}$ & $\mathrm{n}$ & $\mathrm{n}$ & $\%$ & & $\mathrm{n}$ & $\mathrm{n}$ & $\mathrm{n}$ & $\%$ & & $\mathrm{n}$ & $\mathrm{n}$ & $\mathrm{n}$ & $\%$ \\
\hline $\begin{array}{l}\text { Alegre/Feliz/ } \\
\text { Contento }\end{array}$ & 4 & 6 & 10 & 30.30 & $\begin{array}{l}\text { Desilusionado } \\
\text { Decepcionado/ } \\
\text { Defraudado }\end{array}$ & 4 & 3 & 7 & 21.21 & $\begin{array}{l}\text { Enojo/ Moles- } \\
\text { tia/ Frustrado }\end{array}$ & 9 & 3 & 12 & 40 \\
\hline $\begin{array}{l}\text { Bien/ } \\
\text { Satisfecho }\end{array}$ & 4 & 6 & 10 & 30.30 & Normal/Nada & 3 & 2 & 5 & 15.15 & Decepción & 3 & 2 & 5 & 16.67 \\
\hline $\begin{array}{l}\text { Desconfiado/ } \\
\text { Incertidumbre/ } \\
\text { Nervioso }\end{array}$ & 3 & 1 & 4 & 12.12 & $\begin{array}{l}\text { Enojado/ } \\
\text { Molesto/ } \\
\text { Frustrado }\end{array}$ & 2 & 2 & 4 & 12.12 & $\begin{array}{l}\text { Preocupación/ } \\
\text { Incertidumbre }\end{array}$ & 1 & 2 & 3 & 10 \\
\hline Animado & 2 & 0 & 2 & 6.06 & $\begin{array}{l}\text { Triste/ } \\
\text { Desanimada }\end{array}$ & 2 & 2 & 4 & 12.12 & $\begin{array}{l}\text { Aceptación/ } \\
\text { Resignació }\end{array}$ & 1 & 1 & 2 & 6.67 \\
\hline Orgullo & 2 & 0 & 2 & 6.06 & $\begin{array}{l}\text { Inconforme/ } \\
\text { Insatisfecho }\end{array}$ & 1 & 2 & 3 & 9.09 & Nada & 2 & 0 & 2 & 6.67 \\
\hline Indiferencia & 1 & 0 & 1 & 3.03 & $\begin{array}{l}\text { Incertidumbre/ } \\
\text { Miedo }\end{array}$ & 2 & 1 & 3 & 9.09 & Mal & 1 & 0 & 1 & 3.33 \\
\hline Convencida & 0 & 1 & 1 & 3.03 & Seguridad & 2 & 0 & 2 & 6.06 & Nada & 2 & 0 & 2 & 6.67 \\
\hline Aliviado & 1 & 0 & 1 & 3.03 & Bien & 0 & 1 & 1 & 3.03 & Mal & 1 & 0 & 1 & 3.33 \\
\hline Tranquilo & 1 & 0 & 1 & 3.03 & Tranquilo & 1 & 0 & 1 & 3.03 & Indiferente & 1 & 0 & 1 & 2.38 \\
\hline No contestó & 0 & 1 & 1 & 3.03 & Nerviosa & 0 & 1 & 1 & 3.03 & Confianza & 0 & 1 & 1 & 2.38 \\
\hline \multirow[t]{3}{*}{ Total } & 18 & 15 & 33 & $100 \%$ & Resignación & 1 & 0 & 1 & 3.03 & Feliz & 0 & 1 & 1 & 2.38 \\
\hline & & & & & No contestó & 0 & 1 & 1 & 3.03 & Total & 19 & 11 & 30 & $100 \%$ \\
\hline & & & & & Total & 18 & 15 & 33 & $100 \%$ & & & & & \\
\hline
\end{tabular}

Fuente: Elaboración propia con base en los datos de las Entrevistas pre y post electorales.
¿Cómo se siente de que no haya ganado JAMK? cómo se sentiría usted?

$\begin{array}{cccc}\mathrm{H} & \mathrm{M} & & \text { Total } \\ \mathrm{n} & \mathrm{n} & \mathrm{n} & \%\end{array}$


En el caso de las personas votantes por JAMK, si hubiera ganado y según la entrevista preelectoral, los participantes dijeron que se sentirian alegres y felices en casi un tercio (30.30\%), en el mismo porcentaje que se sentirian bien y satisfechas, con incertidumbre y nerviosismo (12.12\%) (Tabla 10).

Quienes se decantaron por la felicidad y la alegría expresaron: "Bien, alegre, satisfecho" (hombre 26 años), "Feliz, porque no ganó Obrador" (mujer 28 años), "Me sentiría alegre al saber que tiene buenas propuestas y ayudaría al pueblo" (hombre 30 años), "feliz y complacida, ya que espero desempeñe muy bien su papel" (mujer 53 años), "Feliz, no habrá repercusiones en el trabajo de mi marido" (mujer 69 años).

Las personas que estarían bien y satisfechas dijeron: "Satisfecho y un poco intranquilo" (hombre 55 años), "Bien, por el hecho de que está alguien que quiere trabajar y mejorar" (mujer 58 años).

Aquellas gentes que afirmaron sentirian nerviosismo e incertidumbre expresaron: "muy nerviosa, con nervios de que no pueda cambiar las cosas" (mujer 22 años) "incertidumbre porque las cuestiones económicas actuales son muy complicadas" (hombre 47 años). Emociones combinadas, "Satisfecho y ansioso por ver que hace el candidato" (hombre 20 años).

A la pregunta de cómo se sentirían si perdía el candidato, hubo quien señaló que sentiría decepción (21.21\%), quien dijo que no sentiría nada (15.15\%) y quien estaría seguramente enojado y frustrado (12.12\%), así como, en similar número y porcentaje, hubo quien dijo tristeza y desánimo.

Las personas decepcionadas afirmaron: "desilusionado, triste, conforme" (hombre 21 años), "Me daría tristeza, es el candidato que yo elegí porque creo en él" (hombre 30 años), "Decepcionada, los demás candidatos no son lo que México necesita" (mujer 39 años), "Defraudado y con un México más mediocre" (hombre 45 años).

Quienes se sintieron frustrados-enojados afirmaron: "frustrado, pero respetando el voto" (hombre 24 años), "Pues enojada y con miedo" (mujer 28 años). Las tristes y desanimadas, "pues un poco de miedo, y tristeza" (hombre 26 años), "Triste y preocupada" (mujer 69 años). Enojo, tristeza por un candidato y miedo e incertidumbre hacia otro: "Con mayor incertidumbre porque el candidato que pudiera ganar solamente está improvisando y no tiene la preparación suficiente" (hombre 47 años).
El tercer asunto es lo que sintieron al no haber sido ganador JAMK, según la entrevista postelectoral, muchos (40\%) afirmaron estar enojados y frustrados, así como, decepcionados (16.67\%) y con incertidumbre-preocupación (10\%).

Quienes sintieron frustración-enojo al perder su candidato afirmaron: "frustrado $\mathrm{y}$ avergonzado" (hombre 24 años), "No lo entendí, a la gente le gusta votar por los populares y no los que están más preparados" (hombre 33 años), "Un poco enojado porque la gente se deja guiar por el partido político, pero la verdad el candidato fue el mejor para el cargo" (hombre 35 años), "Frustrado, por culpa de otras personas pagó el partido y MORENA ganó solo por ser un partido "nuevo" y porque mucha gente cree que los van a sacar de la mediocridad o pobreza" (hombre 39 años).

Aquellos que sintieron decepción afirmaron: "decepcionado y enterado del nivel del hartazgo y lo fácil que es que en tiempos oscuros nazcan falsos profetas, citando a Sabina" (hombre 19 años), "Al principio me sentía decepcionada pero ahorita ya estoy aceptando la derrota" (mujer 20 años). $\mathrm{Y}$ es que, como se mencionó anteriormente, las emociones son proceso y continuum a modo de cadena (Jasper, 2012).

Finalmente, quienes sintieron incertidumbre y preocupación declararon: "preocupada por lo que pueda pasar en el país” (mujer 20 años), "Pues con una gran incertidumbre en el aspecto económico, porque el candidato que ganó no tiene los conocimientos necesarios" (hombre 47 años). $\mathrm{Y}$ aquellos que sintieron aceptación expresaron: "no me siento ni mal ni bien, el pueblo eligió y como somos democracia se debe de respetar lo que la mayoría elija y colaborar con quien sea el presidente" (mujer 64 años). Aceptación entendida del principio de realidad y equilibrio emocional.

\section{Conclusiones}

"Así, las emociones hacen mucho más que añadir color a la elección" (Marcus, Neuman y Mackuenn, 2007, p.263). No en vano antaño se denominaban pasiones y hoy se habla del neuromarketing políticoemocional. Por si dudas hubiera, esta investigación da fe de su importancia.

Lo que aquí se ha presentado de manera general a veces, otras detallada, casi siempre descriptiva, dibuja el panorama emocional-electoral de las elecciones presidenciales del $1^{\circ}$ de julio del 
2018 en México, según una encuesta preelectoral y las entrevistas antes y tras la elección, con datos y relatos de emociones autorreportadas, cumpliendo con el objetivo inicialmente propuesto.

Tras revisar la información y sobre todo los testimonios y su diversidad de emociones, percepciones, sensaciones, creencias, opiniones, valores, explicaciones, según las ideologías políticas partidistas o los apoyos electorales a determinados líderes políticos, bien vale hacer una reflexión $\mathrm{y}$ escuchar las distintas voces $\mathrm{y}$ orientaciones políticas, sus sentimientos y argumentos, tenerlos todos en cuenta, en vez de hacer lo que dice la neuropolítica que hacemos, que solo oímos aquello con lo que estamos de acuerdo, el resto no lo escuchamos o si lo hacemos lo despreciamos (Westen, 2007; Bermejo, 2015). En cualquier caso se espera que las transcripciones aquí mostradas, que reflejan los sentires de algunas personas de la ciudad sobre los candidatos y sus políticas, sirvan para eso, para escuchar y comprender, sin juzgar ni condenar (Hobsbwan, 1980; Morin, 1999), y si es así, este trabajo habrá tenido un cometido noble y una razón de ser respetable, más allá de su aportación académica.

La decisión del voto, si es que se le puede nombrar así todavía, dado que al parecer tiene que ver con una reacción emocional intuitiva e inconsciente que se justifica a posteriori según algunos autores (Bermejo, 2015), no es tan racional como otros creían (Downs, 1957; Riker y Ordeshook, 1968) según la perspectiva clásica como la elección racional, que analiza utilidad-beneficio, lo cual implica estar informado de las propuestas políticas y estudiarlas para decidir por la mejor opción política. Se afirma hoy que la población no siempre quiere o puede estar informada, comprende a fondo la política, y se toma tiempo para deliberar o tomar decisiones (Arias, 2016).

Parece claro que hay que tener en cuenta otras circunstancias, el elector y sus circunstancias, parafraseando a Ortega y Gasset, y aquí añadimos circunstancias emocionales que tienen que ver con la personalidad, el entorno social, la cultura, la ideología política, la campaña, la publicidad, sobre todo la influencia del medio. Todo esto no podemos afirmarlo ni negarlo, lo que sí se puede hacer y se ha hecho, es esbozar las tendencias emocionales del electorado con relación a los candidatos, su triunfo o no triunfo hipotético y lo mismo ya sobre los datos reales tras la elección, lo primero a través de una encuesta y unas entrevistas preelectorales", lo segundo por medio de entrevistas tras la jornada electoral.

La Tabla 11 es un resumen de la encuesta, muestra de la polarización emocional de la población de la CDMX, entre esperanza si gana AMLO y seguridad si los otros candidatos no lo hacen, y enojo si no llega a triunfar.

Tabla 11. Emociones ante el triunfo o no triunfo del candidato

\begin{tabular}{|c|c|c|c|c|c|c|}
\hline \multirow{2}{*}{ Emociones } & \multicolumn{2}{|c|}{ AMLO } & \multicolumn{2}{|c|}{ RAC } & \multicolumn{2}{|c|}{ JAMK } \\
\hline & Gana & $\begin{array}{c}\text { No } \\
\text { gana }\end{array}$ & Gana & $\begin{array}{c}\text { No } \\
\text { gana }\end{array}$ & Gana & $\begin{array}{c}\text { No } \\
\text { gana }\end{array}$ \\
\hline Esperanza & $43.9 \%$ & & & & & \\
\hline Enojo & & $49.1 \%$ & $44.3 \%$ & & $44.8 \%$ & \\
\hline Seguridad & & & & $42 \%$ & & $52.3 \%$ \\
\hline
\end{tabular}

Fuente: Elaboración propia con base en los datos de las Encuesta preelectoral de la Ciudad de México, junio 2018.

Por su parte, la Tabla 12 presenta tendencias de las entrevistas, y si bien no puede exponer su diversidad y riqueza, apunta también la polarización emocional. Si AMLO obtiene la victoria hay esperanza, una vez la obtuvo hay felicidad, de no haber triunfado hubiera habido enojo y miedo, según sus seguidores. Si hubiera ganado RAC hubiera habido esperanza, seguridad, felicidad y satisfacción, al no hacerlo hubo decepción, enojo y miedo según sus electores. Para los votantes de JAMK si este se hubiera hecho con el triunfo hubiera habido seguridad, esperanza, alegría y satisfacción, al no haberlo obtenido hubo enojo y decepción.

Brevemente, para finalizar, es necesario resaltar cómo las teorías inicialmente expuestas, y citadas en la revisión de los datos, y la información de este estudio, tienen perfecta vigencia en la elección presidencial. En cuanto a la Teoría de la inteligencia afectiva (Marcus, 2002) que compagina dos sistemas, es aplicable a la esperanza -en el futuro- y al entusiasmo -en el presente- que dijeron sentir hacia un candidato en especial. No obstante, también sirve para todos como motor del voto y como emoción ligada al posible triunfo o la victoria definitiva, si es el caso. Se trata de emociones y sentimientos basados en la alegría y que direccionan el compromiso y el apoyo, también orgullo del elector hacia el voto. Así también, forma parte la esperanza de los sentimientos morales y las baterías emocionales (Jasper, 2013), que junto 
o en contraposición al enojo, tensan y mueven a la acción, en este caso, a la votación. A la vez tiene que ver con los sueños e ideales de motivación política (Nussbaum, 2014), para un futuro mejor como debería ser (Jasper, 2013). La esperanza se relaciona con el sistema de recompensa en el cerebro, provoca placer e incita a la aceptación (Bermejo, 2015), energiza y vitaliza a la persona (Muñoz, 2009), además del empuje hacia el cambio posible (Fromm, 1984; Bloch, 2007). Otra

Tabla 12. Entrevistas preelectorales y postelectorales

\begin{tabular}{|c|c|c|c|c|c|c|c|c|c|}
\hline \multicolumn{5}{|c|}{ Preelectorales } & \multicolumn{5}{|c|}{ Postelectorales } \\
\hline \multicolumn{10}{|c|}{ Semicerradas } \\
\hline & Gana & & & No gana & & & Votó con & & \\
\hline Emociones & AMLO & RAC & JAMK & AMLO & RAC & JAMK & AMLO & RAC & JAMK \\
\hline Esperanza & 63.83 & 52.63 & 30.30 & & & & 63.64 & & \\
\hline Enojo & & & & 38.30 & 47.37 & 33.33 & & & \\
\hline Miedo & & & & 31.91 & 28.95 & & & & \\
\hline Seguridad & & 36.84 & 39.39 & & & & & 55.76 & 53.33 \\
\hline \multicolumn{10}{|c|}{ Abiertas } \\
\hline & Gana & & & No gana & & & Ganó/no ganó & & \\
\hline & AMLO & RAC & JAMK & AMLO & $\mathrm{RAC}$ & JAMK & AMLO & RAC & JAMK \\
\hline $\begin{array}{l}\text { Felicidad/ } \\
\text { alegría }\end{array}$ & 36.17 & 34.21 & 30.30 & & & & 50.91 & & \\
\hline $\begin{array}{l}\text { Bien/ } \\
\text { satisfacción }\end{array}$ & & 26.32 & 30.30 & & & & 23.91 & & \\
\hline Enojo & & & & 27.66 & & & & & 40 \\
\hline Decepción & & & & & 28.95 & 21.21 & & 28.57 & \\
\hline
\end{tabular}

Fuente: Elaboración propia con base en los datos de las Entrevistas pre y postelectorales, junio y julio 2018.

emoción destacada en estas páginas es el enojo -descontento, hartazgo, ira- ya mencionada como parte de la batería moral que representa un daño pasado o presente y moviliza a la defensa de la justicia (Jasper, 2013). Esta, a su vez, conlleva intranquilidad y no apoyo a quien la causa. Manifiesta atención, búsqueda de información, alejamiento (Marcus, 2002) y posible que también genere reconsideración y cambio de preferencias electorales. Es parte de la impotencia ante la falta de justicia, mueve a la defensa de la dignidad y el respeto como parte de la cognición evaluativa y moral (Nussbaum, 2018), a la movilización y acción social (Jasper, 2011). El enojo provoca en el cerebro aversión hacia algo que duele o algo considerado peligroso, hay que alejarse o defenderse (Bermejo, 2015).
La seguridad, aquí identificada con afecto (Muñoz, 2009) como emoción básica, aunque también considerada necesidad (Maslow, 1982) es parte del sistema de disposición (Marcus, 2002) y emparenta con la calma y la confianza. Por lo que también apoya la intención de voto, como se ha visto.

El miedo tan enarbolado en esta y otras campañas anteriores, sí tuvo presencia, su origen parece multicausal, forma parte de restar apoyo y votos a quien lo inspira (Marcus, 2002), en la línea similar al enojo, aunque no parece haber sido muy importante.

Luego hay una cauda de emociones que son expuestas en los cuadros ilustrativos de las entrevistas y en los relatos de los testimonios, pero tienen menor importancia como tendencia 
numérica del sentir emocional. Estas emociones mueven a votar o a retirar el voto hacia un candidato, por supuesto son empleadas por estos y sus campañas, que la población dice sentir y que como hoy sabemos que configuran la cognición, la evaluación, la moral y la política, además de tener influencia directa en el sufragio, como se espera haber mostrado a lo largo de estas páginas al entrecruzarlas con las preferencias electorales y el voto ejercido. Las mismas que también ilustran de manera clara y amplia, la polarización del clima emocional, o mejor dicho, la polarización políticoemocional que tuvo lugar alrededor de la elección presidencial en México en el año 2018.

\section{Referencias}

Arias, M. (2016). La democracia sentimental. Barcelona, España: Página indómita.

Bermejo, P. (2015). Quiero tu voto. Madrid, España: LID.

Bloch, E. (2007). El principio de la esperanza. Madrid, España: Trotta.

Damasio, A. (2006). El error de Descartes. Barcelona, España: Crítica.

Downs, A. (1957). An Economic Theory of Democracy. Nueva York, Estados Unidos: Harper Collins Publishers.

Eagleman, D. (2013). Incógnito. Barcelona, España: Anagrama.

Eagleman, D. (2017). El cerebro. Nuestra historia. Barcelona, España: Anagrama.

Filliozat, I. (2007). El corazón tiene sus razones. Barcelona, España: Urano.

Fromm, E. (1984). La revolución de la esperanza. México: FCE.

Hobsbwan, E. (1980). Historia del siglo XX. México: FCE.

Jaspers, J. (1997). The Art of Moral Protest: Culture, Biography, and Creativity in Social Movements. Chicago, Estados Unidos: University Press. https://doi.org/10.7208/chicago/9780226394961.001.0001

Jasper, J.M. (2012). ¿De la estructura a la acción? La teoría de los movimientos sociales después de los grandes paradigmas. Sociológica, 27, 7-48. Recuperado de: https://www.redalyc.org/pdf/3050/305024717001.pdf

Jasper, J.M. (2013). Las emociones y los movimientos sociales: veinte años de teoría e

investigación. RELACES, 10, 48-68. Recuperado de: https:// www.redalyc.org/articulo.oa?id=273224904005

Khanemann, D. (2013). Pensar rápido, pensar despacio. Barcelona, España: Debolsillo.

Marcus, G. (2002). The Sentimental Citizen. Pensilvania, Estados Unidos: University Press.

Marcus, G., Newman, R. y Mackuenn, M. (2007a). Inteligencia afectiva y juicio político.
Primera parte. Sociológica, 22 (63), 253266. Recuperado de: https://www.redalyc.org/ pdf/3050/305026593011.pdf

Marcus, G., Newman, R. y Mackuenn, M. (2007b). Inteligencia afectiva y juicio político. Segunda parte. Sociológica, 22 (64), 241-267. Recuperado de: https://www.redalyc.org/articulo.oa?id=305024715010

Maslow, A. (1982). La amplitud potencial de la naturaleza humana. México: Trillas.

Moore, B. (1985). La injusticia: bases sociales de la obediencia y la rebelión México: UNAM.

Morin, E. (1999). El método. El conocimiento del conocimiento. Madrid, España: Cátedra.

Muñoz, M. (2009). Emociones, sentimientos y necesidades. Una aproximación humanista. México: IHPG.

Nussbaum, M. (2012). Paisajes del pensamiento. Barcelona, España: Paidós.

Nussbaum, M. (2014). Emociones políticas. Barcelona, España: Paidós.

Nussbaum, M. (2018). La ira y el perdón. México: FCE.

Riker, W. y Ordeshook, P. (1968). A Theory of the Calculus of Voting. American Political Science Review, 63(1), 28-38. https://doi.org/10.2307/1953324

Sanders, K., Canel M.J., Capdevila, A. y Gurrionero, M. (Coords.) (2008). Estudios de comunicación política. Madrid, España: Tecnos.

Westen, D. (2007). The Political Brain. Nueva York, Estados Unidos: Public Addairs. 